\title{
FROM SURVEY TO MODEL, AND RETURN. THE CASE OF THE PARMA BAPTISTERY
}

\author{
A. Zerbi ${ }^{a}$, S. Mikolajewska ${ }^{\text {a }}$ \\ ${ }^{a}$ Università degli Studi di Parma, Dipartimento di Ingegneria e Architettura, Parco Area delle Scienze 181A, 43124, \\ andrea.zerbi@unipr.it, sandra.mikolajewska@studenti.unipr.it
}

\section{Commission II}

KEY WORDS: Cultural Heritage, Parma baptistery, Photogrammetry, Laser scanning, Modelling, Integration

\begin{abstract}
:
Although this is not always the common practice, the survey should be an essential preliminary stage to any operation of restoration, enhancement and promotion of cultural heritage. Today, various surveying techniques make it possible to collect large amounts of data quickly and to provide a complete three-dimensional representation of extremely complex artefacts. In fact, 3D models allow a much richer description than traditional 2D representations. However, these survey techniques (laser scanner and photogrammetry above all) necessarily imply that the data that must be elaborated during the processing phase increase dramatically. It is therefore essential to identify methods and workflows that allow to find a compromise between the richness and completeness of the survey data and the problems inherent in the costs and times of execution of the modelling operations. The problem is further heightened by the fact that the importance of historical monumental architecture inevitably requires the use of different techniques integrated with each other, the production of documentation at different scales with different levels of detail and the creation of a 3D model that has the ability to be used for different purposes. This paper describes the survey of one of the most important medieval monuments in northern Italy, the Parma Baptistery, with a special focus on the phase of data restitution. The integrated survey campaigns conducted in recent years have aimed to describe the building in its totality: from the scale of the architecture to the detail, passing through the description of the pictorial cycle that characterizes the interior. This case study represents a moment of reflection, at least for those who wrote it, on the validity of the methods and techniques to be used for the creation of a complete 3D model of a complex historical monument.
\end{abstract}

\section{INTRODUCTION}

Each study aimed at the knowledge of an important and complex cultural heritage is always an extremely delicate operation, since it involves multiple disciplines, each of which, with its own operators and sensibilities, is able to approach the topic in a different way. It is also true, however, that there are some operations that can be considered invariant whatever the type of analysis or intervention one intends to carry out on the object under investigation. Among these, architectural survey is one of the most important and essential steps.

The modern technologies available today allow a complete three-dimensional reconstruction of the study object. The choice of which particular method/tool to use may depend on several factors including the purpose for which the 3D model is made, the geometric and material characteristics of the artifact, the morphological conditions of the context, the budget available and the experience of the operators (Remondino et al., 2014). More specifically, the reasons that lead to the choice of using a particular surveying method and particular tools for its threedimensional restitution may be of a different type. They change according to the purposes that the study in progress aims: for documentation (De Luca, 2011; Verdiani, 2017), for dissemination and enhancement (Apollonio, 2012), for restoration, for maintenance (Oreni et al., 2014), for monitoring and structural calculation (Battini et al., 2017).

In the field of cultural heritage, largely characterized by complex and articulated architectures, most of the time the methodology of survey is the result of the combination of different technologies (Remondino, 2011; Fassi, 2011), each of which is characterized by specific advantages and able to compensate for any limitations of each technique. Not only are they able to obtain information about the product with an extremely high level of accuracy, but they also achieve these results in much shorter times than traditional surveying methods.

The so-called reality-based techniques, based on the use of passive sensors (including photogrammetry) and active sensors (present in laser scanners or total stations), document the state of reality at the precise moment of the survey. If on the one hand their integration represents a well-established and consolidated system, on the other hand the phase of data processing, especially as regards the survey of historical monumental architecture, still presents several open questions. The main challenges concern the transformation of the point clouds obtained from the survey campaigns into defined geometric elements (Docci, 2004) that are as close as possible to the reality and, at the same time, easily manageable.

The past experiences of modelling through the use of meshes, i.e. polygonal surfaces built on the point clouds resulting from the survey, applied to the context of complex buildings with large dimensions have shown several problems due to the difficulties of data management.

In response to this issue, several experiments have recently been conducted on the use of BIM (Building Information Modeling) procedures on cultural heritage (Lo Turco et al. 2016; Murphy et al., 2013). However, this approach, designed for new buildings and therefore based on the use of parametric elements, still presents several critical issues related to the modeling of historical buildings, characterized by the presence of nonstandardizable elements and therefore not connected to the predefined libraries offered by software currently on the market. 
At the moment, there is no single modelling methodology suitable for the numerous cases of cultural heritage, easily adaptable to different scales and at the same time easily manageable.

However, it remains certain that the result of a threedimensional survey on cultural heritage is able to provide information on the building with extreme accuracy, acting as a real digital archive of the same, which can be investigated at any time and on multiple fronts of research (Cardaci et al., 2013). Not only does it allow the extrapolation of information related to geometric-dimensional data, but it also makes possible a series of analyses aimed at verifying the state of preservation of the building, including colorimetric surveys. Last but not least, the possibility of using such data in the field of the enhancement and dissemination of the cultural heritage, which has become so important in the Italian context.

In this context, this article aims to test the combination of the most widespread technologies of survey and three-dimensional modeling on one of the most interesting monuments of the city of Parma, the Baptistery of San Giovanni (see Figure 1), unanimously considered a sort of link between Romanesque and Gothic architecture.

The research carried out aims in particular to test the limits and potential of the three-dimensional model in the specific context of the survey for the restoration of cultural heritage. To this purpose, a digital model of the Baptistery describing the monument in its entirety was created using direct modelling procedures. In the future, this model could be used as a threedimensional information system, to share with other professionals, through which extract all relevant information, for example for the execution of operations to safeguard the monument.

In order to highlight the potential offered today by the instrumental survey, a comparison was also made between the drawings produced during this research and those relating to the most famous survey of the monument, represented by the seventeen extraordinary illustrations engraved by G. Bertoluzzi and P. Sottili during the nineteenth century.

\section{PARMA BAPTISTERY CASE STUDY}

The construction of the Parma Baptistery, located in Piazza Duomo between the Cathedral and the Bishop's Palace, begun by Benedict Antelami in 1196, when the practice of building isolates baptisteries had been abandoned in almost all of Europe. Although it was probably completed in the early 1300s, the building was able to accommodate the first baptismal rite on Holy Saturday, 9 April 1216. Almost all scholars, in fact, agree that the vault was painted between 1250 and 1270, overlapping an earlier plaster decoration. During the fourteenth century were then made the balustrade on the roof, the various pinnacles and other works of secondary relevance that led to the completion of the building.

If we exclude all the works of consolidation, restoration, maintenance and furnishing of the interiors that have concerned the building from the fifteenth century onwards, we can say that the Baptistery has come to us substantially in its fourteenthcentury state.

Today it is the Fabbriceria del Duomo that takes care of its maintenance and all the restoration operations to which a monument of medieval origin must inevitably be continuously subjected. The analysis of the existing documentation immediately confirmed that the Baptistery was no longer object of an organic survey campaign from the second half of the nineteenth century to the present day. In fact, excluding some technical drawings made between the end of the eighteenth and the beginning of the nineteenth century, not very reliable from a geometric and dimensional point of view, the first systematic survey of the Parma Baptistery was carried out by Abbot Giacomo Francini in the early nineteenth century. The drawings were personally designed by Francini and document an extremely precise survey for the period, almost all relating to the crowning part of the building. Francini's drawings document every element from general to detailed scale. It should be noted that everything concerning the decorative apparatus, both sculptural and pictorial, instead of being represented directly on the elevations and sections, is replaced by a description (relative to the frescoes), or by a number that refers to further large-scale drawings.

In 1864 Michele Lopez published the first text entirely dedicated to the systematic study of the Antelami's monument (Lopez, 1864). Inside the volume are collected the prints of what is still today the most precise architectural survey of the building, realized by G.Bertoluzzi and engraved in the Toschi Studio in Parma by Bertoluzzi and P.Sottili (see Figure 2). The seventeen illustrations testify to an accurate surveying operation, with regard to the general system of the building and the decorative apparatus. In fact, these representations, surely influenced by the drawings made by Francini, are enriched by a large number of decorative details, a documentation of the carved and painted parts, but above all by detailed analysis of the different constructive solutions of the architectural elements (sections of the portals, sections of the loggias, etc.).

Perhaps due to the richness and the fascination of the drawings attached to the volume of Lopez, until today the building has not been subjected to any complete survey campaign. Among the partial surveys carried out in the last years for the most different purposes, we can only mention those realized during the restoration works conducted by Bruno Zanardi between 1986 and 1992, limited to the illustration of the marble slabs

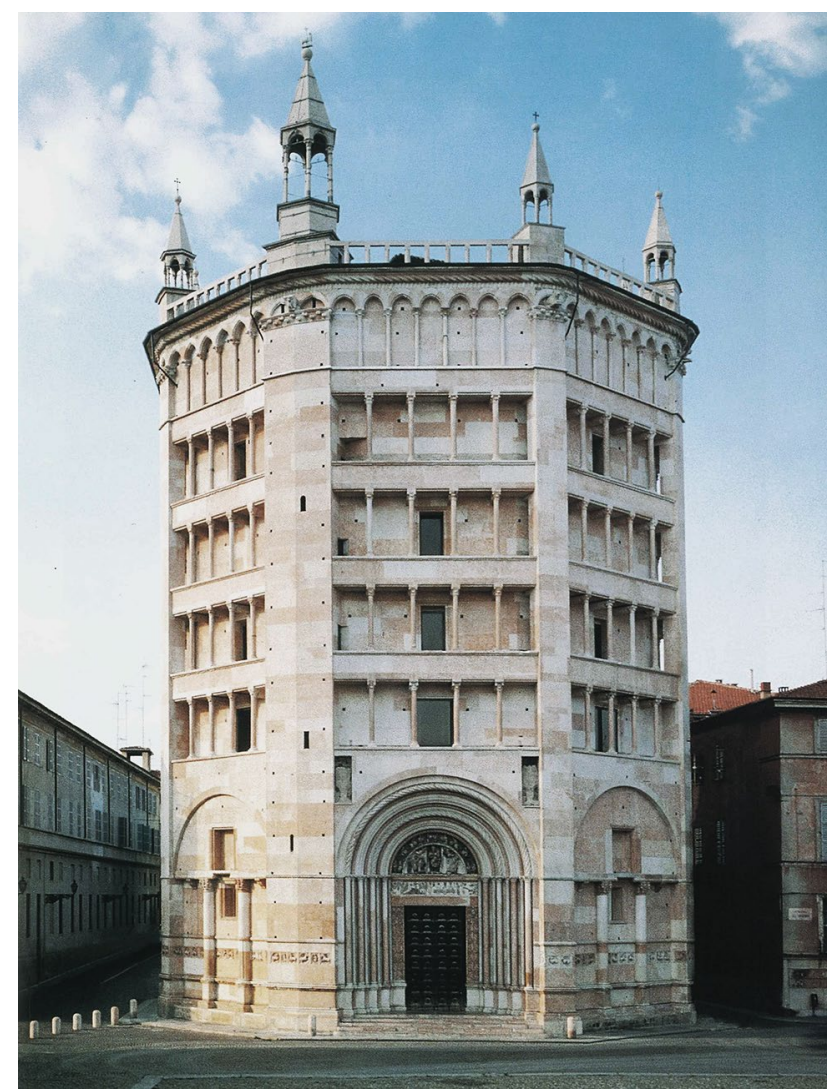

Figure 1. The Parma baptistery. 


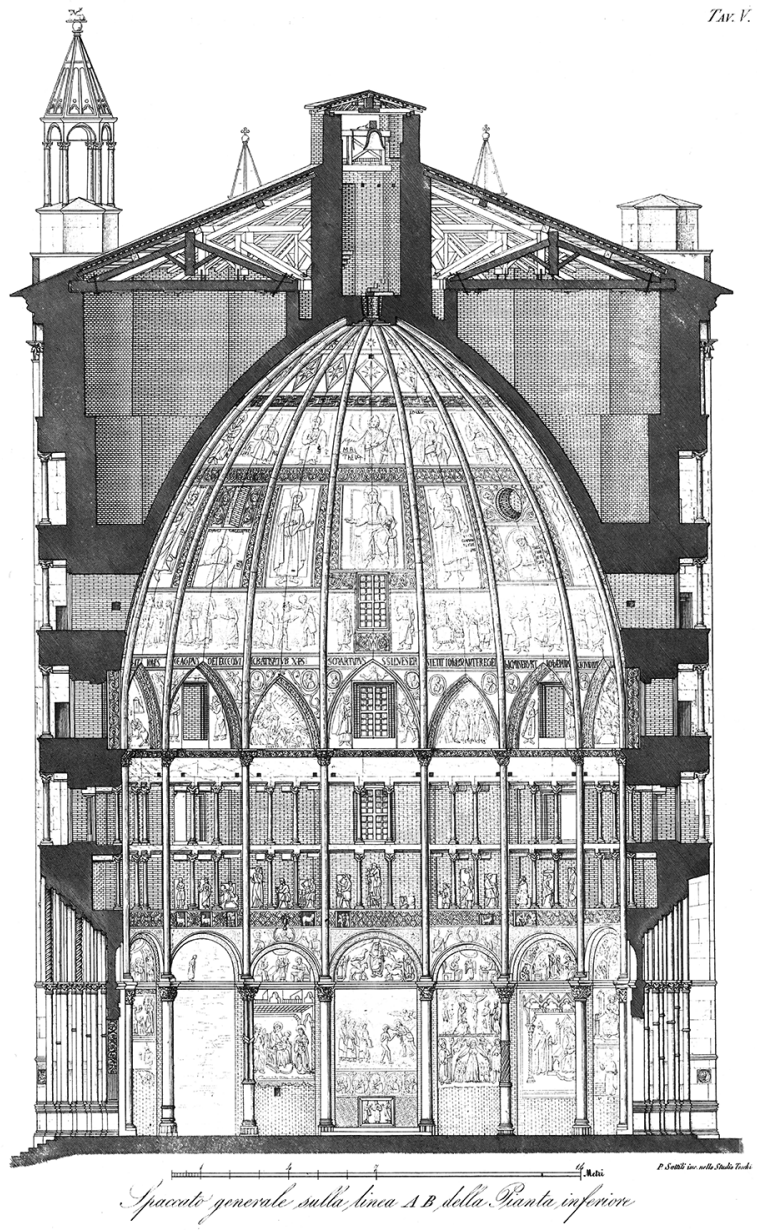

Figure 2. G. Bertoluzzi, P. Sottili: vertical section of the Parma baptistery (1864).

system of the external cladding and a photogrammetric survey of the vault made by Fo.A.R.T. in 1993 for study purposes.

From 1864 the Parma Baptistery was no longer organically surveyed, although the building, from 1825 onwards, has been subjected to continuous and more or less substantial restoration campaigns.

One of the fundamental reasons for this approach must be the fact that, despite the historical importance of the monument, restoration operations have always been carried out according to the logics of programmed maintenance or extraordinary maintenance. The activity of restorers, more or less the same for long periods of time, has therefore always inevitably followed common, consolidated and repeated over time procedures. Even for reasons of containment of costs, they have never needed accurate surveys, if not very partial ones. It is useless to underline how this operative practice, which is common to a large part of the Italian monumental heritage, must be changed, since it does not allow to leave a sign of the transformations undergone by an artefact over time.

On the basis of these considerations, starting from 2012, some important campaigns have been carried out by the DIA (Department of Engineering and Architecture) of the University of Parma. The aim of these operations was the creation of a series of 3D models of the entire building that could constitute a fundamental tool for the management of all restoration operations to which the building will be subjected in the future and that would allow to verify the validity and accuracy of the drawings published in 1864 by Michele Lopez, as part of research on historical representations of the Baptistery.

\section{THE SURVEY}

The building is characterized by an extraordinary decorative apparatus and by constructive and decorative choices that make it look more like an enormous sculpture than an architectural construction. It is sufficient to observe the red Verona marble that characterizes the entire exterior of the monument, where the overlapping loggias seem to have been carved into a single block of stone, or its capitals that are configured as the sculptural decoration of the terminal part of the marble shelves used to support the loggias themselves. It was precisely this characteristic that made it necessary to carry out some preliminary considerations regarding the survey methodologies and the choice of techniques to be used.

The survey of the Baptistery was therefore planned according to the shape, size and above described characteristics of the building. The accurate planning of the operations and survey techniques allows to optimize all the subsequent phases of data restitution and to save time during the campaign operations. In this specific case, it was decided to use two different survey techniques: a laser scanner survey intended for a geometric and dimensional definition of the entire building on the architectural scale and a photogrammetric survey intended to correctly reproduce the pictorial apparatus of the interiors and to define the correct dimensions and geometries of the plastic apparatus on the scale of detail. On the one hand, this choice has made it possible to reduce the number of stations and the resolution of the scans of the laser scanner survey, and on the other hand, it has made it possible to focus the attention of the photogrammetric survey mainly on the sculptural apparatus. In fact, it was immediately decided to use the laser scanner survey for the correct georeferencing of individual photogrammetric surveys.

The Parma Baptistery, with an octagonal plan externally, faces in part Piazza Duomo, the small Piazza del Battistero and some small-sized streets. The surveys on the side of the square have the obvious benefit of being able to stand at ground level wherever you want and the disadvantage of not being able to occupy high positions. On the other hand, the survey building's sides that overlook the secondary road network presents some problems due to the limited space to be able to move away adequately from the building but has the advantage of having the possibility to place stations at higher altitudes in some surrounding buildings. Each side of the octagon is separated from the adjacent one by a pier that goes from the ground to the roof. The south, west and north sides have three portals in the lower part, characterized by a strong splay intended to accommodate slim columns standing on pedestals and a rich plastic apparatus. The other five sides are characterized by the presence of as many round blind arches, each of which contains a pair of semi-columns. Above this first order there are four loggias in which the space is scanned by four columns on each side. This conformation of the higher areas has inevitably determined the impossibility of completely removing some shadow areas. The top part of the building is characterized by the presence of lancet blind arches whose number changes between six and seven, depending on the side.

Inside the monument its plan becomes decaesagonal, with sides of variable length. Each side, with the exception of the three that contain the portals, is characterized by the presence in the lower part of a large niche covered by a hemispherical cap separated from those adjacent by columns. As for the external part, above the niches there are two levels of linteled loggias. 
Given the reduction in the length of the internal sides, each loggia has only two columns and is separated from the adjacent by columns placed above those below that separate the niches. As for the outside, also in this case it was impossible to avoid some shadow areas due to the impossibility of stationing on the loggias, which are not accessible. The second internal loggia is located at the level of the first external loggia and is thus able to accommodate the first level of openings that give light to the central space. The interior of the monument is covered by a large pavilion vault divided into sixteen spindles and completely frescoed, like almost all of the rest of the interior space. A rich sculptural apparatus, extremely varied and heterogeneous, never repetitive, completes the decoration of the building.

Two small spiral staircases are placed inside the two main piers. They connect the various levels of the internal and external loggias and allow access to the extrados of the vault and the roof. The connection between the various levels of the building therefore presents numerous problems linked to the impossibility of using staircases as a connecting element between stations, unless extremely complex operations that would probably have invalidated the reliability of the measurements collected. It was then decided to use a survey methodology based on the employment of appropriately positioned targets, so that they could be seen both from the central area and from the crawl space, using the presence of some openings in the vault.

\subsection{Laser-scanner survey}

Because of the size of the building and the inaccessibility of many parts of it, the survey was conducted using mainly indirect methods of measurement. On the building, both internally and externally, 111 targets were placed, whose position was uniquely determined by a topographic survey. In order to guarantee the correctness of the measurement operations, two closed and linked traverses were carried out, which were subsequently compensated in the post-processing phase. The survey of the targets allowed the creation of a first point cloud that formed the basis for the subsequent laser scanner survey.

Outside the building, the laser scanner (Leica C10 time of flight Scan Station) was placed in 14 points at the front of the sides of the octagon and the piers. Unfortunately, given the particular conditions of the urban context, characterized by the presence of some buildings located near the Baptistery, it was not possible to place stations in all places where it would have been best to do so. At each of these 14 stations, two scans were carried out, relating to the lower part and the upper part of the building. In order to keep the density of points throughout the building as constant as possible, for these scans it was decided to use a different resolution. The point clouds were then acquired at a sampling rate of about 8 millimetres, uniform vertically and horizontally. Five other stations were placed in an elevated position: one on the terrace of a building on the south of the Baptistery, two at the first floor of the Minor Seminary, located on the east of the Antelami's monument, and two from the top of the Cathedral Bell Tower, using the temporary scaffolding set up to carry out some restoration work. Given the impossibility of placing the laser scanner in a position that would allow to see the targets on the Baptistery, in the postprocessing phase it was essential to proceed to the recording of the point clouds collected from these last scans by using homologous points. To conclude the survey of the outside two further $360^{\circ}$ scans were carried out from two different points of Piazza Duomo in order to document the relationship that the

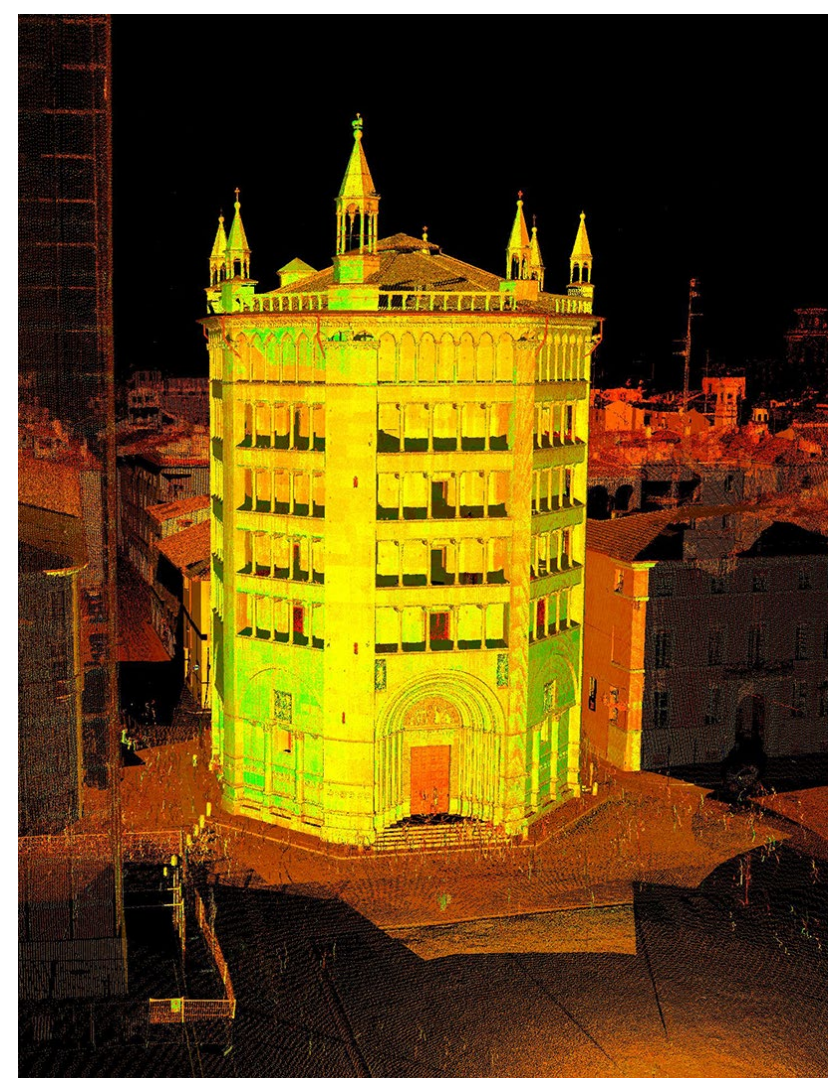

Figure 3. Point cloud from laser-scanning survey.

building establishes with the urban environment in which it is located.

Inside the monument, the laser scanner has been placed in five points in the central space: four in correspondence to the cardinal points, i.e. in the centre of the sides of the octagon relative to the three portals and the altar, and one exactly in the centre, inside the large polygonal baptismal font. Eight more stations were placed in the crawl space. To connect the scans made by the latter with those made in the central space, were used the targets placed inside the building, which were collimated by placing the instrument in correspondence of the openings located in the vault.

A total of 50 scans were carried out from the 34 points where the instrument was placed. Their registration was carried out keeping as a reference the topographic network. The control of the registration of the clouds showed that the maximum error is always contained within $1 \mathrm{~cm}$ (see Figure 3).

\subsection{Photogrammetric survey}

In parallel with the laser scanner survey, several photogrammetric surveys were carried out, aimed in particular at documenting in detail the internal pictorial apparatus and the sculptural apparatus present both inside and outside the building. For both, a Nikon D3x with a resolution of $6048 \times 4032$ pixel and $35 \mathrm{~mm}$ and $50 \mathrm{~mm}$ optics has been used.

Although the laser scanner used is provided with an integrated camera, a photogrammetric survey was also carried out in order to obtain better results with regard to the restitution of the frescoes that cover almost all the monument's surfaces. A total of more than 250 images were taken from about eighty different points located at the center of each of the 16 sides, both at the floor level of the central space and at the level of the second internal loggia. Because of a series of difficulties linked in particular to the impossibility of obscuring the 24 windows that 
illuminate the interior, three images with different expositions were taken from each point. It was only during the processing phase that it was decided which images to use. The latter were then oriented in the reference system chosen through the targets previously detected with the total station and the laser scanner. The DSM was generated with Agisoft Photoscan (Agisoft Photoscan, 2018), which was then used for the production of orthophotos.

As regards the survey of the sculptural apparatus, at the moment a couple of tests have been carried out on some elements of Zoophoros, that develops on the outside of the building. For the execution of the photogrammetric survey it was possible to benefit from the presence of a temporary scaffolding that allowed to reach the height at which the adorned with figures slabs are placed. Each slab has a height of about $45 \mathrm{~cm}$ and a variable width, especially depending on whether a single slab of marble contains a single bas-relief or two. For each single slab about 25 images were acquired, for the double one about 50 . Thanks to the above-mentioned scaffolding, it was possible to acquire images from a distance of less than one meter (with 35 $\mathrm{mm}$ optics), thus minimizing the shadow areas.

\section{DATA PROCESSING}

At the end of the survey campaigns it was decided to create a three-dimensional digital model of the monument. The peculiarities of the building, characterized by a rich plastic apparatus within a historical structure of large dimensions, led to the decision not to use a parametric software for the modelling of the architecture, but a free form one. This choice was supported by the fact that modelling a building of such high complexity for mesh surfaces would have been almost impossible, since the point cloud of the entire monument is too difficult to manage, being made up of an extremely high number of points. As it was necessary to create a simplified version of the monument but made up mainly of elements that are difficult to adapt to the serialisation typical of parametric modelling, it was decided to operate through direct modelling.

The first operation carried out was to create, starting from the point cloud, a series of two-dimensional sections. Eight plans were then extrapolated at the most significant levels of the building and eight vertical sections along the main axes of the monument. In order to extract from the cloud all the information necessary for the complete three-dimensional restitution of the work, based therefore on extremely precise geometric and dimensional data, further sections of detail have been realized in correspondence of particularly complex parts.

For the creation of the digital model of the Baptistery, each surface was created individually within the Rhinoceros software (Rhinoceros, 2018), using the geometric modelling approach. For all the elements that can be identified as geometrical elements, and so considered as mathematical surfaces, NURBS surfaces were employed. Specifically, in the case of planar surfaces, two-dimensional profiles were extruded along the relative directing paths. For the architectural details such as entablatures, sections were sliding along one or more paths. Finally, the curved surfaces such as compartments of the dome were created from the edge curves. The latter, characterized by inaccuracies in construction and structural failures, were realized through the discretization of their actual geometry obtained directly from the creation of mesh surface from the point cloud. This operation was fundamental for the understanding of the geometric genesis of the elements, which allowed their correct regularization in the three-dimensional reconstruction.
However, it should be noted that all modelling operations have been constantly compared with the starting data consisting in the point cloud. The latter was used as a reference element for the construction of the "skin" of the building and allowed to identify immediately any anomalies or construction inaccuracies that were then immediately reported correctly in the digital model (see Figure 4).

At the moment, in order not to generate a too complex and unmanageable model, it was chosen to simplify and, in other cases, completely overlook the modelling of the detailed sculptural decoration that characterizes the entire building. The latter was the subject of detailed modelling carried out in parallel with the creation of the general model but developed through different methodology. The aim was to create different models on different scales, but connected to each other, in order to always be able to trace, depending on the purpose of the particular research in progress, both information about the building and its decorative apparatus.

At the end of the modelling operations, the obtained result was compared with the original data represented by the TLS point cloud within the software PolyworksInspector (Polyworks, 2018). The comparison showed an RMS error of $0.006188 \mathrm{~m}$. This operation, in addition to quantifying numerically the correspondence between the two virtual models, highlights in a punctual manner the parts of the building characterized by the highest deviation. The main differences concern in particular the decorative apparatus, which in this specific model it was decided to omit, the elements placed on the roof, and those subject to deformation and degradation phenomena, such as the continuous stone basement. In fact, some elements of

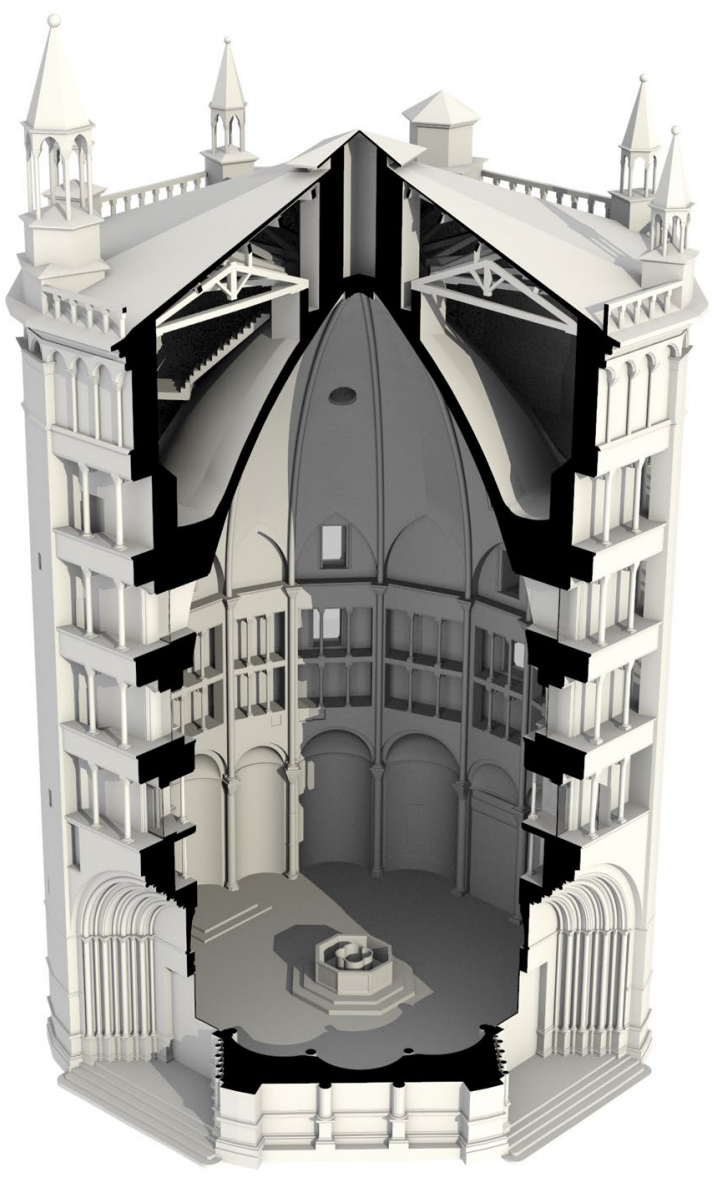

Figure 4. 3D model of the Parma baptistery. 


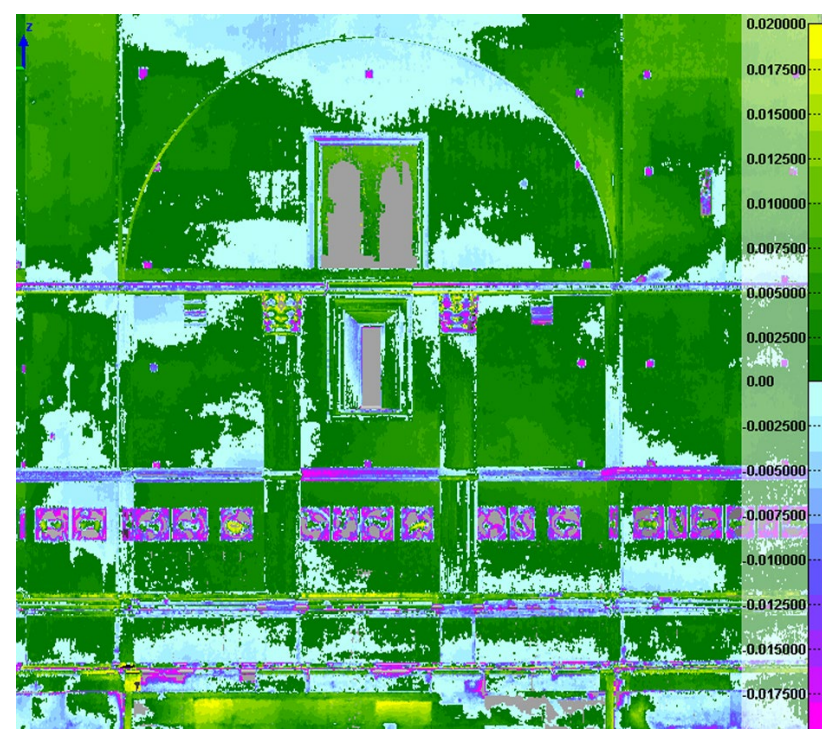

Figure 5. Particular of the comparison map [m] between the TLS point cloud and the 3D model of the baptistery.

decoration located mainly in the lower part of the building, such as the continuous frames that surround the entire monument, have numerous lacks and are in a not good state of conservation. In order to obtain a digital model that adheres to the current state of these elements, it would have been necessary to use mesh surfaces, which would have excessively overloaded the model. For this reason, for the elements subject to particularly significant degradation phenomena it was decided to operate through the regularization of the geometry, reproducing their hypothetical original state. The comparison operation, allowing immediately to identify the areas on which to operate in order to obtain the digital model as close as possible to the monument, becomes a real control tool, essential in the modelling of the cultural heritage (see Figure 5).

The digital model produced not only accurately documents the state of the monument at the specific time of the survey, but also acts as a support tool for any type of intervention. At any time, in fact, through its section with appropriate reference plans, it will be possible to extrapolate the necessary twodimensional drawings, even in the parts not commonly documented in traditional drawings.

As already mentioned, at the same time as the general model of the building was developed, detailed mesh models of the sculptural apparatus were created. In the case shown here (the slabs representing "Due buoi accosciati") the acquired frames were processed within the software Agisoft Photoscan that allowed to obtain a point cloud consisting of 26 million points. In order to make the cloud more manageable and to reduce data processing times, it was subjected to a series of operations through the Geomagic software (Geomagic, 2018). The first operations carried out were to reduce the inevitably noise of the point cloud and fill some gaps in correspondence of very small shadow areas that could not be avoided in the phase of acquisition of the images. The cloud has therefore been decimated and used to generate a mesh model consisting of more than 27 million triangles. Because of the excessive number of polygons, also the obtained mesh model has been decimated and optimized (removal of noise, elimination of intersections, filling of holes). It was then necessary to segment the mesh according to the richness of the details of the individual parts characterizing the slab. In order to obtain a number of triangles extremely reduced in the flat parts and a higher number in the parts characterized by evident discontinuity due to the plasticity of the sculpture and the signs left by time, each part was then further decimated using different percentages of reduction. At the end of the operations it was obtained a model consisting of about 630.000 triangles that was imported back into Photoscan for the generation of the texture (see Figure 6).

With the aim of connecting the photogrammetric survey of the sculptural apparatus with the laser scanner survey carried out on the entire monument, the same reference system was used. To this end, some GCP have been extracted from the TLS point cloud, which are necessary to orient the model of the slab in an absolute way. In this case, it is always possible to import the detail models on the overall 3D model at any time.

Finally, always starting from the photogrammetric survey, the

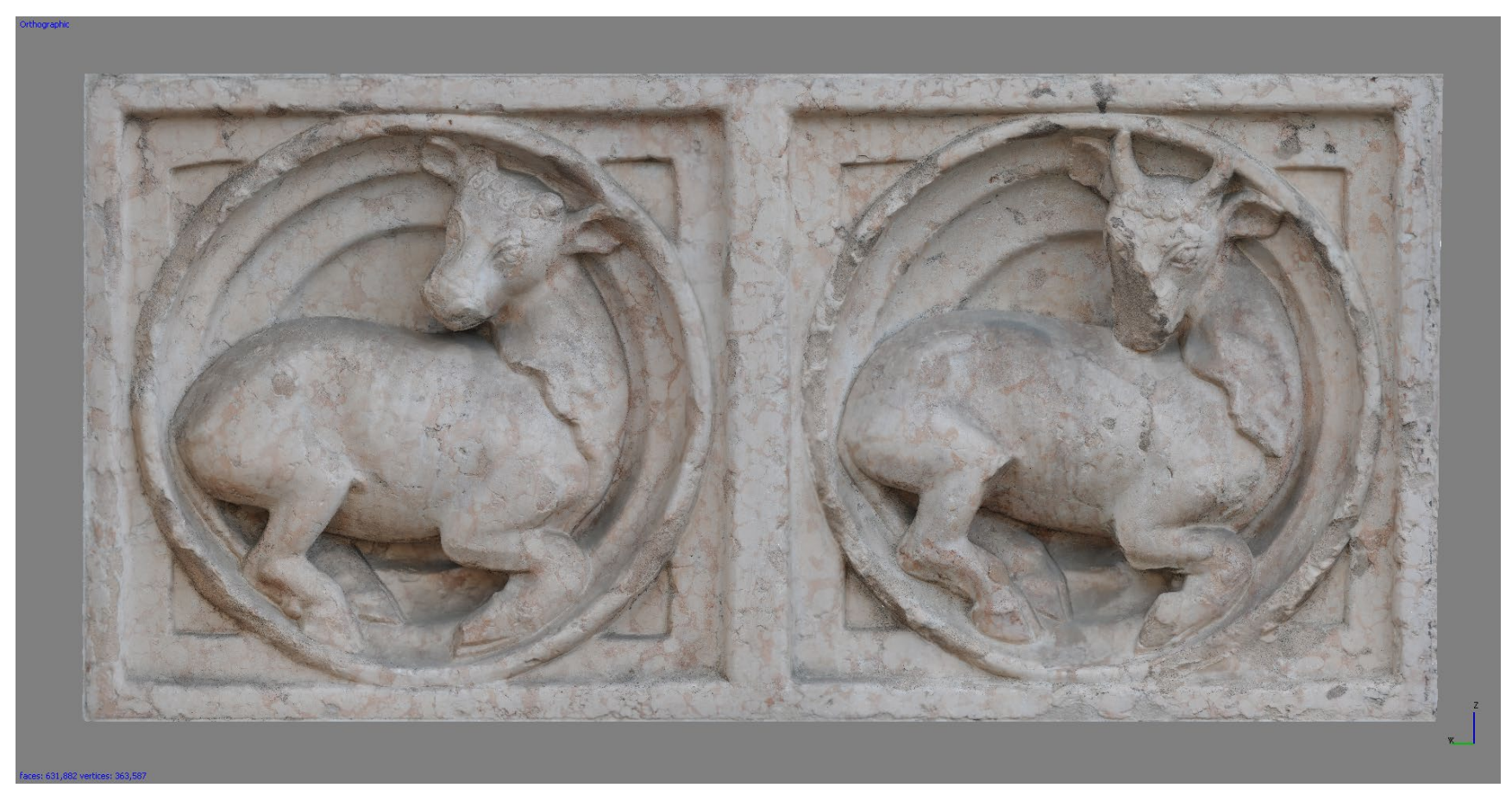

Figure 6. Photogrammetric model of a slab located on the zooforo of the Parma baptistery. 


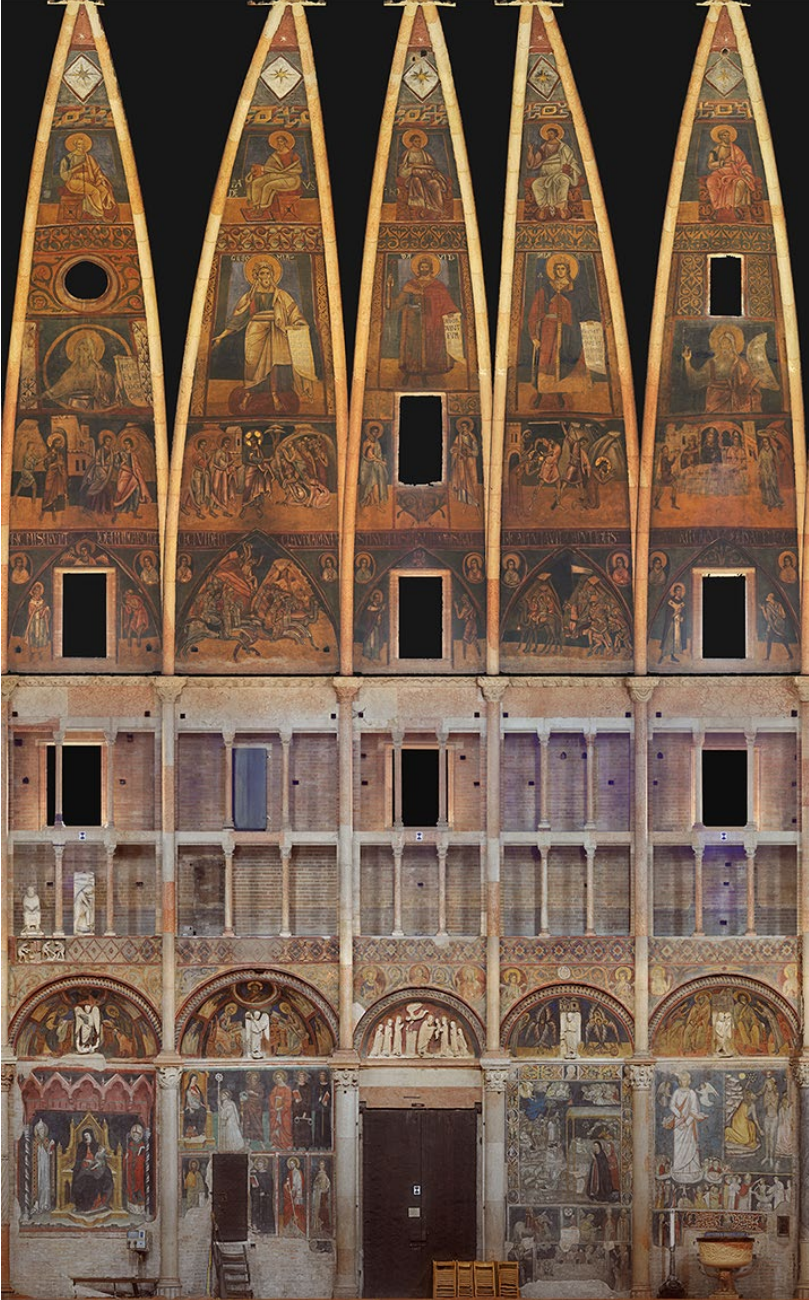

Figure 7. Particular of the ortophoto of the interior.

orthophotos were made, for the moment limited to the internal part of the building. In order to document in detail the rich fourteenth-century pictorial apparatus that characterizes the dome and the niches of the Baptistery, the development of the 16 internal sides was produced (see Figure 7).

\section{COMPARISON BETWEEN PAST AND PRESENT SURVEY DRAWINGS}

If on the one hand a reliable model represents today an essential basis for any operation aimed at the dissemination and enhancement of Cultural Heritage, on the other hand it offers new opportunities for investigation in different sectors such as restoration and historical studies. For example, the survey presented here made it possible to analyse the Bertoluzzi's drawings realized in 1867 and printed in the monograph of Lopez, still considered the most precise architectural survey of the Parma Baptistery.

The comparison was carried out only on the general drawings (plans, sections and elevations) and not on those of detail for which the operation would have been less significant. The first operation undertaken was to vectorialize all the prints. Afterwards, the problem of the correct scaling of the engravings was examined. In this regard, two approaches have been used: on the one hand, directly on the illustrations attached to the monograph of Lopez, and on the other, on the second chapter of the text, where the author reports all the measures of the building that he considered fundamental. From this first

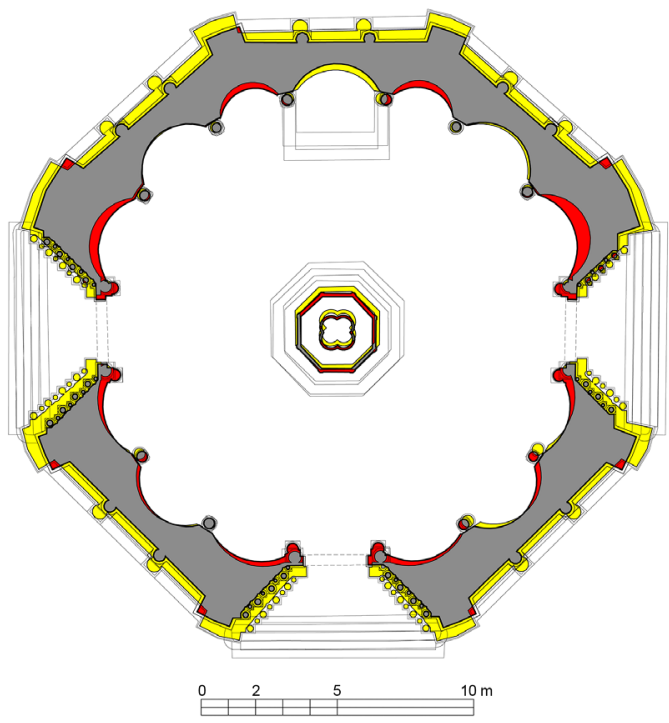

Figure 8. Comparison between the plan of G. Bertoluzzi and that produced by the current survey. In yellow are indicated the parts in which Bertoluzzi places masonry not present in reality. In red are represented actually existing parts, but not indicated in the nineteenth-century drawings.

comparison it was possible to see that there is not perfect consistency between the measures indicated in the text and the printed drawings. Therefore, not willing to make arbitrary choices, it was preferred to resize the drawings according to the graphic scale present on each of them.

For example, the comparison of the plan of the first level is presented here (see Figure 8). In the elaboration proposed here, the discrepancies are highlighted using the typical modalities of representation of the comparison drawings. For an easier reading, this work was limited to the sectioned parts only, omitting all the parts in sight. It appears evident that Bertoluzzi attributed much wider wall thicknesses than the real ones. Moreover, all the niches differ from their actual configuration. In addition, rotations and translations are present almost everywhere. Similar differences can also be found in the plan of the upper level and, amplified, in the sections and elevations. In conclusion, the drawings on which studies and restorations have been based over the last 150 years, although extraordinary in their graphic representation, are characterised by an extremely evident incongruities in all parts. This observation is not intended in any way to invalidate the validity of the nineteenthcentury survey, but to bring to attention the fact that the digital model created today can also be used for the analysis of studies carried out in other periods.

\section{FINAL CONSIDERATIONS AND CONCLUSIONS}

The creation of 3D models for cultural heritage is now an increasingly common practice. Their use is beginning to be widespread, especially in the field of enhancement and dissemination as well as in restoration. Even recent experiences related to the use of BIM applied to existing buildings, as well as to new buildings, has also encouraged the creation of $3 \mathrm{D}$ models with the most different characteristics. In this context, it is increasingly important to invest time and resources for technological development and scientific research aimed at optimizing techniques and procedures for the creation of $3 \mathrm{D}$ models from the survey data. Today, this operation has to face 
several critical issues mainly related to two factors: on the one hand, the extremely long execution times, especially if compared to the speed with which the survey campaigns are carried out, on the other hand, the level of adherence of the model to the survey data so that the model itself can be considered as acceptable. From this point of view, it is unquestionable that the use of parametric modelling software, capable of significantly reducing time of many operations, on the other hand leads to levels of simplification of reality that cannot always be justified.

In this context the work here presented proposes a workflow aimed at documenting in its entirety complex architectures through the creation of multiscale 3D models. Each of them is characterized by a quite small size in terms of memory allocated and, at the same time, adequate adherence to the original survey data. Obviously there is no ambition to solve any problem, especially in view of the fact that processing times remain too long. However, it is also true that the survey, today more than ever, must be considered as an open system of knowledge (Cundari, 2003) and consequently can and must be continuously implemented and updated over time. This being so, once the main reference model, which can already be used for various purposes, has been produced, further detailed models can be realized in different times according to the needs that arise from time to time.

\section{REFERENCES}

Agisoft Photoscan - http://www.agisoft.com/ - (February 2018).

Battini, C., Vecchiattini, R., 2017. Survey and restoration. New ways of interaction. In: The International Archives of the Photogrammetry, Remote Sensing and Spatial Information Sciences, Volume XLII-5/W1, 2017, pp. 655-662.

Cardaci, A., Gallina, D., Versaci, A., 2013. Laser scanner 3D per lo studio e la catalogazione dell'archeologia medievale: la chiesa di Santa Croce in Bergamo. Archeologia e Calcolatori, 24, pp. 209-229.

Cundari, C., 2003. Il rilievo nel processo di salvaguardia del complesso monastico di Monteoliveto a Napoli, in: Fiorucci, T., Chiavoni, E. (Editors), Gli strumenti di conoscenza per il progetto di restauro, atti del Seminario Internazionale di Studi, Gangemi Editore, Roma.

De Luca, L., 2011. La fotomodellazione architettonica. Rilievo, modellazione, rappresentazione di edifici a partire da fotografie. Dario Flaccovio Editore, Palermo.

Docci, M., 2004, Rilevamento integrato e modelli virtuali 3D: modellazione ed esplorazione interattiva dell'architettura della città. In: Metodi e tecniche integrate di rilevamento per la realizzazione di modelli virtuali dell'architettura della città, pp. 19-23.

Fassi, F., Achille, C., Fregonese, L., 2011. Surveying and modelling the main spire of Milan Cathedral using multiple data sources. In: The Photogrammetric Record, 26 (136), pp.462487.

doi: $10.1111 /$ j.1477-9730.2011.00658.x

Geomagic - https://it.3dsystems.com/software/geomagic-wrap/ (July 2018).
Lopez M., 2005. Il battistero di Parma descritto da Michele Lopez. Monte Università Parma, Parma.

Murphy, M., McGovern, E., Pavia, S., 2013. Historic Building Information Modelling - Adding intelligence to laser and image based surveys of European classical architecture. In: ISPRS Journal of Photogrammetry and Remote Sensing, Vol. 76, pp. 89-102.

https://doi.org/10.1016/j.isprsjprs.2012.11.006

Oreni, D., Brumana, R., Della Torre, S., Banfi, F., Barazzetti, L., Previtali, M., 2014. Survey turned into Hbim: the restoration and the work involved concerning the basilica di Collemaggio after the earthquake (l'Aquila). In: ISPRS Annals of the Photogrammetry, Remote Sensing and Spatial Information Sciences, Vol II-5, pp. 267-273.

doi:10.5194/isprsannals-II-5-267-2014.

\section{Polyworks}

https://www.innovmetric.com/it/prodotti/polyworks-inspector/ (July 2018).

Remondino, F., Spera, M. G., Nocerino, E., Menna, F., Nex F., 2014. State of the art in high density image matching. In: The Photogrammetric Record, 29(146), pp.144-166. doi: 10.1111/phor.12063.

Remondino, F., 2011. 3D surveying and modelling of complex architectural sites and heritage objects. DisegnareCon, Vol. 4, n.8, pp. $90-98$.

Rhinoceros - https://www.rhino3d.com/it/ - (February 2018).

Lo Turco, M., Santagatia, C., 2016. From structure from motion to historical building information modeling: populating a semantic-aware library of architectural elements. In: Journal of Electronic Imaging, 26.

doi: 10.1117/1.JEI.26.1.011007.

Verdiani, G., 2017. Fortifications and documentation: the case of Fortezza Vecchia in Livorno. State of the digital survey. In: Defensive Architecture of the Mediterranean XV to XVIII centuries, Vol. VI, pp. 311-318. 